\title{
Discoloration and force degradation of orthodontic elastomeric ligatures
}

Samaneh Nakhaei ${ }^{1}$ Raha Habib Agahi², Amin Aminian³, Masoud Rezaeizadeh4

DOI: http://dx.doi.org/10.1590/2177-6709.22.2.045-054.oar

Objective: The aim of the present study was to evaluate color changes and force degradation of orthodontic elastomeric ligatures in different stretching patterns during a 8 -weeks period. Methods: Two elastomers with the minimum and two with the maximum color changing, and gray elastomers of two brands (American Orthodontics and Ortho Technology) were selected according to an opinion poll with clinicians and color changes after 4 weeks of intraoral use were evaluated. These elastomers were mounted on special jigs fabricated using a CAD-CAM technique, underwent different stretching patterns and the force was measured in 0,24 hours, 2, 4 and 8 weeks. During in vivo part of the study, force levels of elastomers were measured after 4 weeks on a material testing machine. Data were analyzed with four-way ANOVA and Tukey post hoc tests. Results: All the elastomers showed color changing but the degree of color stability was significantly different. The mean force degradation was higher in 1-mm stretch groups. After 8 weeks, the average residual force of elastomers was $1.45 \pm 0.18 \mathrm{~N}$ and the maximum force decay was seen in the elastomers that exhibited the maximum initial force. Conclusion: There is significant relationship between the stretching pattern and the amount of residual force of elastomers. Elastomers with higher initial forces exhibited higher percentages of force loss after 8 weeks. It seems that there is a relationship between initial color and color changing of elastomers.

Keywords: Color. Elastomers. Orthodontics. Force degradation.

Objetivo: o objetivo do presente estudo foi avaliar as alterações de cor e a degradação da força de ligaduras elásticas em diferentes padrões de estiramento, durante um período de 8 semanas. Métodos: duas ligaduras elásticas com alteração mínima de cor, duas com alteração máxima de cor e ligaduras elásticas na cor cinza de duas marcas comerciais (American Orthodontics e Ortho Technology) foram selecionadas de acordo com uma pesquisa de opinião com clínicos, e mediante a avaliação das alterações de cor após quatro semanas em uso intrabucal. Essas ligaduras elásticas foram montadas em jigs fabricados por meio da técnica CAD-CAM e foram expostas a diferentes padrões de estiramento, e a força foi medida nos tempos de $0 \mathrm{~h}, 24 \mathrm{~h} ; 2,4 \mathrm{e} 8$ semanas. Durante a parte in vivo do estudo, os níveis de força das ligaduras elásticas foram medidos após 4 semanas, em uma máquina de teste de materiais. Os dados foram analisados com os testes ANOVA de quatro vias e post-hoc de Turkey. Resultados: todas as ligaduras elásticas mostraram alterações de cor, mas houve diferenças significativas quanto ao grau de estabilidade da cor. A média de degradação da força foi

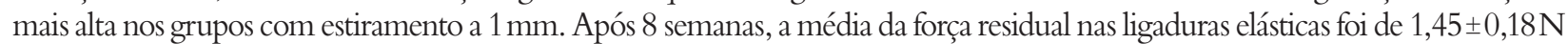
e a maior degradação na força foi observada nas ligaduras elásticas que apresentaram a maior força inicial. Conclusão: há uma relação significativa entre o padrão de estiramento e a quantidade de força residual nas ligaduras elásticas. As ligaduras elásticas com as maiores forças iniciais exibiram as mais altas porcentagens de degradação da força após 8 semanas. É, também, possível que haja uma relação entre a cor inicial da ligadura elástica e sua alteração de cor.

Palavras-chave: Cor. Ligaduras elásticas. Ortodontia. Degradação de força.

${ }^{1}$ Assistant Professor, Department of Orthodontics, Birjand Dental School, Birjand University of Medical Science, Birjand, Iran.

${ }^{2}$ Oral and Dental Disease Research Center, Kerman Dental School, Kerman University of Medical Science, Kerman, Iran.

${ }^{3}$ Assistant Professor, Oral and Dental Diseases Research center, Department of Orthodontics, Kerman Dental School, Kerman University of Medical Science, Kerman, Iran.

${ }^{4}$ Assistant Professor, Graduate University of Advanced Technology, Mechanical Engineering Department, Kerman, Iran.
How to cite this article: Nakhaei S, Habib Agahi R, Aminian A, Rezaeizadeh M. Discoloration and force degradation of orthodontic elastomeric ligatures. Dental Press J Orthod. 2017 Mar-Apr;22(2):45-54. DOI: http://dx.doi.org/10.1590/2177-6709.22.2.045-054.oar

» The authors report no commercial, proprietary or financial interest in the products or companies described in this article.

Submitted: February 18, 2016 - Revised and accepted: August 27, 2016 Contact address: Raha Habib Agahi

E-mail: raha2979@yahoo.com 


\section{INTRODUCTION}

Clinicians may use pins, stainless steel ligature; self ligating clips and circular elastomers to ligate orthodontic archwires to the brackets. ${ }^{1,2}$ Elastomeric ligatures are most commonly used by clinicians due to their several advantages including low cost, easy application, reduced chair time, patient comfort and satisfaction. ${ }^{3}$

These ligatures are manufactured by many companies in a variety of different colors that meet the growing global demand for esthetic orthodontic appliances. Also, the possibility of choosing the ligatures color facilitate young people adhesion to treatment. ${ }^{4}$ Although adding pigments to ligatures seems to represent a great advantage, there is two concerns regarding colored elastomers. The first one is that clinicians and patients may choose ligatures of pleasing color at placement time, but this chosen color is susceptible to color degradation over time, which is a critical concern. Ardeshna et $a 1^{5}$ reported that food diet may affect elastomers color. The second question is whether force delivery is affected by adding pigments to elastomers. Oliveira et $\mathrm{al}^{6}$ reported that elastomers of different colors have different initial force and residual force over time.

The important clinical issue about elastomers is force delivery and force degradation of these materials over time. The force exerted by elastomers depends on the initial force and force decay rate, many studies reported 50-70\% force loss in the first 24 hours. ${ }^{3,4,6}$

Under clinical conditions, differently from usual laboratory conditions in force decay studies, the wire is not placed uniformly within the bracket slot and is not passive. Normally, during the early stages of treatment, high-stress areas that are under tension are produced in the ligature, depending on the extent of tooth misalignment and the differences in the buccolingual position of adjacent teeth. In studies carried out so far on elastomers, less attention has been paid to the exact simulation of the clinical situation and to the effect of stretching on the elastic properties of elastomers. In this study an attempt to evaluate the relationship between stretching pattern and the elastic properties of elastomeric modules as close to the clinical situation as possible was made by designing a specific instrument using CAD-CAM technology.

Knowledge about changes in the physical (like color changes) and mechanical properties (like force delivery) of elastomers is of great interest for their clinical application. ${ }^{7}$ Since elastomers might remain in the oral cavity for an average of 30 days, it is very important to preserve their properties, including force consistency and color stability, and their relationship during this period. ${ }^{5,89}$

In this study, an attempt was made to evaluate color changes and force degradation of orthodontic elastomeric ligatures under different stretching conditions over a period of 8 weeks, and test the hypothesis that elastomeric ligatures of different color under different stretching pattern have different force decay rates.

\section{MATERIAL AND METHODS}

To determine the elastomers which exhibit the maximum and minimum color changes from one orthodontic treatment session to another, different colors of the most commonly used elastomeric ligatures (Unistick, American Orthodontics, USA; Power Sticks, Ortho Technology, USA) were selected and delivered to ten orthodontists, along with questionnaires. All the orthodontists had at least three years of experience working with those commercial brands. Based on the results of an opinion poll with these clinicians, two colored elastomers with maximum color changes and two colored elastomers with minimum color changes were selected from each brand, adding up to eight colored elastomers (Table 1). In the process of selecting the elastomers with the smallest and largest color changes, the next step was an intraoral stage: forty fixed orthodontic patients with good oral hygiene and no specific type of diet were assigned to two groups $(n=20)$, by simple randomization. Four selected colored elastomers of each brand were placed in the oral cavity of 20 patients from each group. Selected ligatures from each brand were placed in a crisscross pattern on teeth \#4 and \#5 in each quadrant to preserve esthetic appearance and to avoid the bias resulting from the patient's eating on only one side. After thirty days, the ligatures were removed from the oral environment, separated by quadrant and the brands were identified by numbers. A total of 168 photographs [ 8 at $\mathrm{T}_{1}$ (not used elastomers), and 160 at $\mathrm{T}_{2}$ (elastomers after 30 days use in oral cavity)], were obtained using a digital camera (Canon EF-S 18-55-IS II, Canon, Osaka, Japan), with a 10-megapixel resolution and color depth of 12 bits. All the photographs were taken manually by a single operator around noon under natural light, without the use of a flash, with 1/6 seconds speed, f/22 diaphragm aperture, ISO 200, 
Table 1 - Percentage of color changing in elastomeric ligatures based on clinician's opinion* of digital photograph.

\begin{tabular}{|c|c|c|c|c|c|}
\hline \multicolumn{3}{|c|}{ American Orthodontics } & \multicolumn{3}{|c|}{ Ortho Technology } \\
\hline Color & $\begin{array}{c}\text { Color changing } \\
\text { score* }\end{array}$ & $\begin{array}{l}\text { Percentage of } \\
\text { color changing }\end{array}$ & Color & $\begin{array}{l}\text { Color changing } \\
\text { score* }\end{array}$ & $\begin{array}{l}\text { Percentage of } \\
\text { color changing }\end{array}$ \\
\hline \multirow{4}{*}{ Red } & 1 & $63 \%$ & \multirow{4}{*}{ Red } & 1 & $58 \%$ \\
\hline & 2 & $27 \%$ & & 2 & $29 \%$ \\
\hline & 3 & $10 \%$ & & 3 & $13 \%$ \\
\hline & 1 & $55 \%$ & & 1 & $51 \%$ \\
\hline \multirow{3}{*}{ Blue } & 2 & $28 \%$ & \multirow{3}{*}{ Cobalt blue } & 2 & $34 \%$ \\
\hline & 3 & $17 \%$ & & 3 & $15 \%$ \\
\hline & 1 & $24 \%$ & & 1 & $21 \%$ \\
\hline \multirow{3}{*}{ Pink } & 2 & $30 \%$ & \multirow{3}{*}{ Violet } & 2 & $27 \%$ \\
\hline & 3 & $46 \%$ & & 3 & $52 \%$ \\
\hline & 1 & $15 \%$ & & 1 & $10 \%$ \\
\hline \multirow{2}{*}{ Bubble gum pink } & 2 & $28 \%$ & \multirow{2}{*}{ Fuchsia } & 2 & $27 \%$ \\
\hline & 3 & $57 \%$ & & 3 & $63 \%$ \\
\hline
\end{tabular}

*Color changing score: 1 = unpigmented ligatures; 2 = pigmented ligatures; 3 = heavily pigmented ligatures

self-timer mode set to trigger after 15 seconds. The images were stored in JPEG format (Fig 1). In order to carry out a visual analysis of the elastomeric ligatures, a Power Point presentation was created. The images were assessed independently by a panel of two orthodontists who rated the degree of discoloration of the elastomeric ligatures using a numerical scale ranging from 1 to 3 , in which 1 was assigned to unpigmented ligatures, 2 to moderately pigmented ligatures, and 3 to heavily pigmented ligatures (Table 1). Finally, from each brand, one elastomer with the most color change and one elastomer with the least color change under clinical conditions were selected. The gray color elastomers from each brand served as control group.

Two types of storage jigs for '1-mm point stretch' and 'uniform stretch' groups were designed and fabricated by using a CAD-CAM technique (Fig 2) in which the designing process (CAD) was carried out with the software SolidWorks 2011 (3D design, SolidWorks Corp., USA) and the manufacturing phase (CAM) was carried out with a CNC machine (VMC Machine, model 850, Machine Sazi Tabriz corp., Iran) and Power MILL software (Delcam corp., UK). The 'uniform stretch' jig was prepared from a rectangular aluminum bar measuring $2.9 \times 1.1 \mathrm{~mm}$, equal to the width of a premolar bracket (Gemini Metal bracket, 0.022-in slot, 3M Unitek). The '1-mm point stretch' jigs were designed to simulate the elastomers stretch condition during the first stage of fixed orthodontic treatment with malpositioned teeth. To create stretch and stress points in elastomers, 0.016-in SS wires were used (Fig 3). These holding jigs were used to store the elastomers during the study period in containers with artificial saliva in an incubator at $37 \pm 1^{\circ} \mathrm{C}$ under a traction force. All the elastomer groups were tested for force on a materials testing machine (model 10 KN, M350-10CT, Testometric Company, UK). The ligatures were stretched at a rate of $5 \mathrm{~mm}$ per minute until rupture according to Kovatch et $\mathrm{a}^{10}{ }^{10}$ study. As each elastomer was stretched, force $(\mathrm{N})$ was constantly measured and recorded. Force-extension curve was plotted by WinTest Analysis Materials Testing software (Testometric Company, UK). The fixture of materials testing machine was designed by the CAD-CAM technique and was manufactured from two equal-sized aluminum cubes, with two semi-circular rods, measuring $1.1 \mathrm{~mm}$ in radius (Fig 4). At the beginning of the test the two halves of the fixture were placed next to each other with no space between them, hence producing a 2.2-mm diameter circle. To calculate distance between the two parts of fixture (Fig 4) at which the force levels of elastomeric modules were measured (' $X$ ' in Fig 4), the inner circumferences of the elastomer on the fixture of the testing machine were adjusted to match the inner cir- 


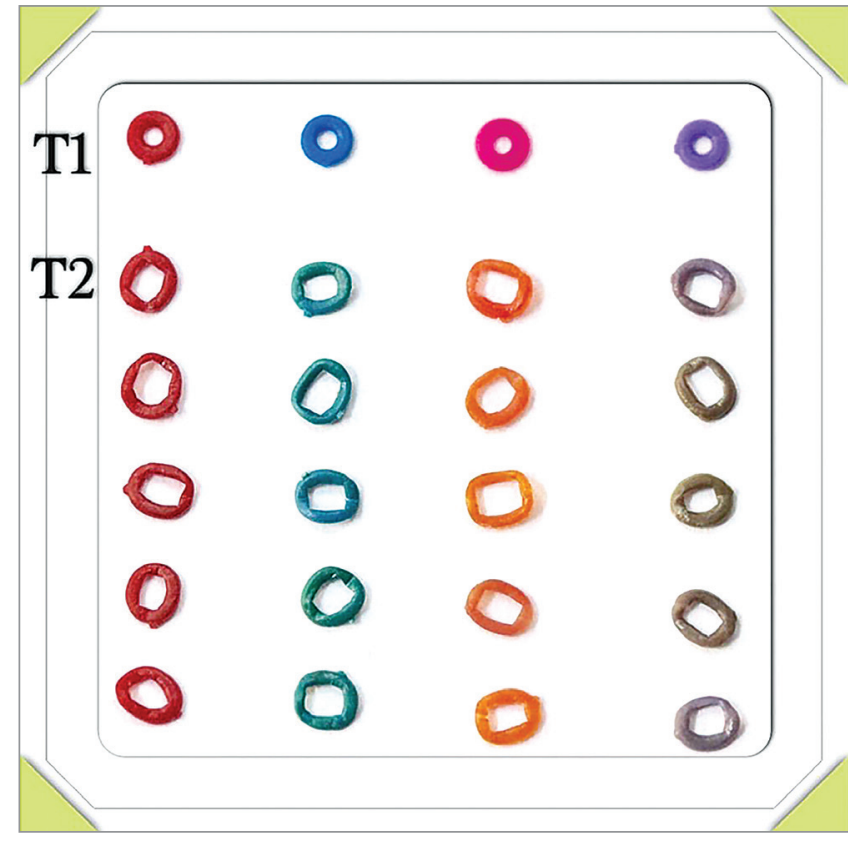

Figure 1 - Photographic evaluation of color changing of elastomers after intraoral use (T1: not used elastomers, T2: intraoral used elastomers).

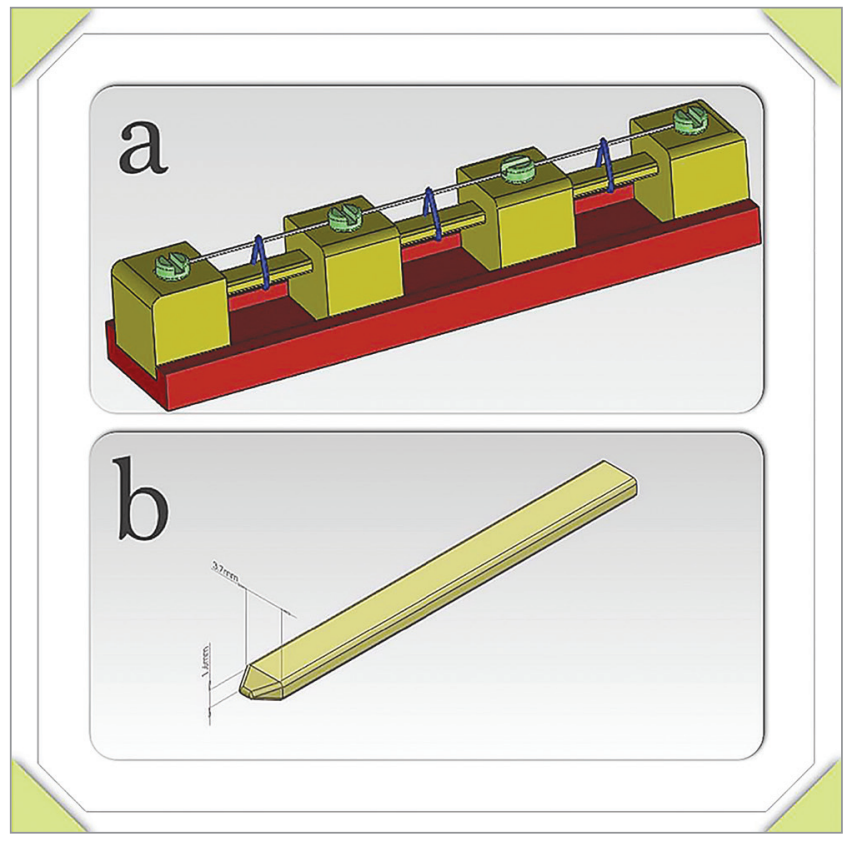

Figure 2 - CAD-CAM fabricated jigs ( $\mathrm{A}=1$ - $\mathrm{mm}$ point stretch jig, $\mathbf{B}=$ uniformstretch jig). cumferences of the specimens placed on the storage jigs of the relevant groups, and all the measurements were made at 0.1-mm accuracy, using SolidWorks software. The ' $\mathrm{X}$ ' distance was calculated for all groups using the following formula:

$$
\begin{gathered}
X=y-2 z \\
2
\end{gathered}
$$

Whereas:

$y=$ the circumference of the elastomer on the storage jig;

$z=$ the circumference of the half-circle of the fixture.

$\mathrm{X}$ was calculated at $1.5 \mathrm{~mm}$ in the 'uniform stretch' group and at $2 \mathrm{~mm}$ in the ' $1-\mathrm{mm}$ point stretch' group. A total of 10 elastomers from each color were tested for the amount of initial force and residual force after 24 hours, 2, 4 and 8 weeks in the two groups with uniform and 1-mm point stretch patterns.
In order to confirm the accuracy of the results of the in vitro study with the results of the intraoral study, 10 elastomeric ligatures from each three selected colors (least color change, most color change, control) from both companies were placed on the premolar teeth of 10 patients using fixed appliances. They all used 3M-Unitek bracket system and were in the finishing stage with 0.016-in SS archwires. In order to make the in vitro and the oral cavity conditions as similar as possible, the elastomers were placed in both conditions with a ligature gun (Straight Shooter, TP Orthodontics, USA). The elastomers were retrieved from the oral cavity at a 4-week interval, rinsed with copious distilled water and placed in artificial saliva. The forces were measured in less than 30 minutes on a materials testing machine. Sixty samples were evaluated in the intraoral stage and a total of 600 samples were evaluated in the present study (Fig 5). 


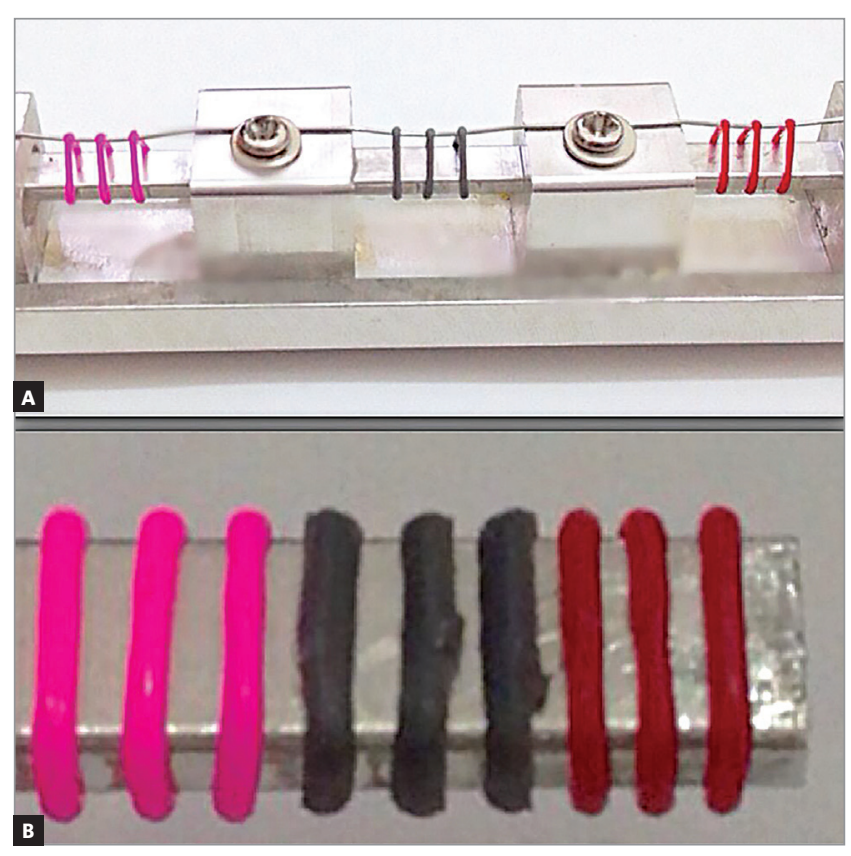

Figure 3 - The 1-mm point (A) and the uniform stretch (B) jigs.

A study of ethics in medical ethics committee reviewed and approved the research. The aim of the study was explained to the patients, which voluntarily participated in the study. Informed consent to participate in the study was obtained from patients before their involvement and they were given a choice to leave the study whenever they want. Patient's data were all kept confidential, and they did not had to pay any additional costs to take part in the study. Photographs were taken including only premolar of the patients, pictures of the face were not taken, to follow the ethical guidelines.

The SPSS software v.18 (SPSS Inc. Chicago, IL, USA) was used for statistical analysis of data (at significance level of $p<0.05)$. Descriptive statistics were used to report the clinician's opinion regarding the most commonly used colored elastomers and photographic evaluation of elastomers with minimum and maximum color

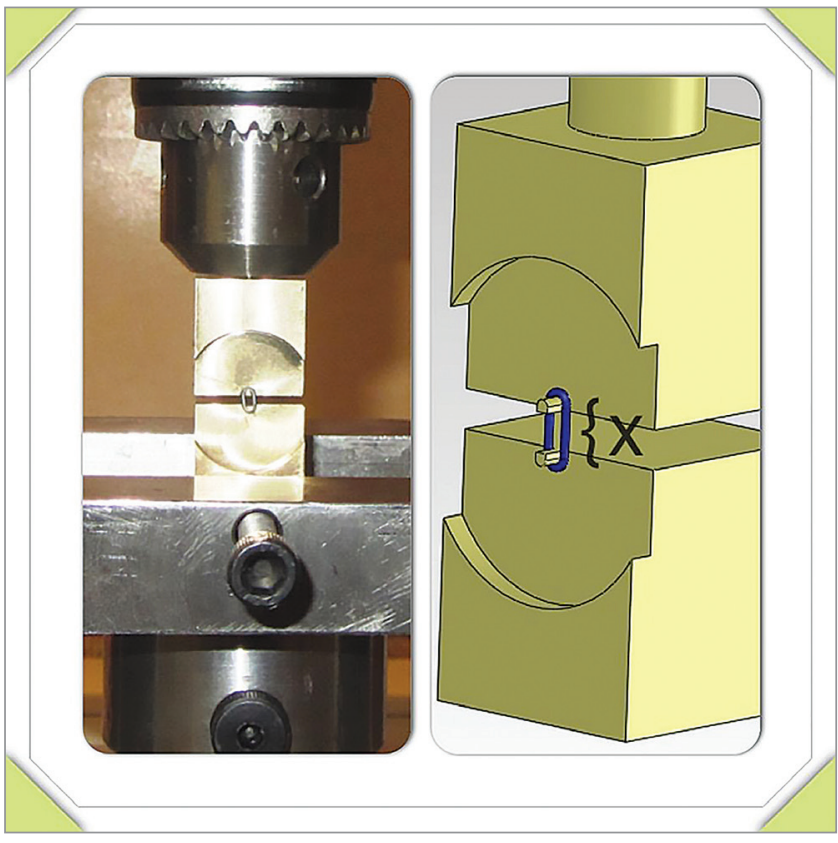

Figure 4 - Fixture fabricated for testometric machine.

changes in the mouth. Results of force measurements were statistically analyzed with four-way ANOVA using brands, stretching pattern (uniform versus 1-mm), color and time as variables, followed by Tukey post-hoc tests.

\section{RESULTS}

According to results of the opinion poll, American Orthodontics (AO) red and blue elastomers, and Ortho Technology (OT) cobalt blue and red elastomers were selected as the ones with minimum color changes, and AO bubble-gum pink and pink elastomers, and OT violet and fuchsia elastomers were selected as the ones with maximum color changes. Based on photographic evaluation (Fig 1), red elastomers of both companies were rated as the ones with minimum color changes, and $\mathrm{AO}$ bubble-gum pink elastomer and OT fuchsia elastomer were rated as the ones with maximum color changes (Table 1). 


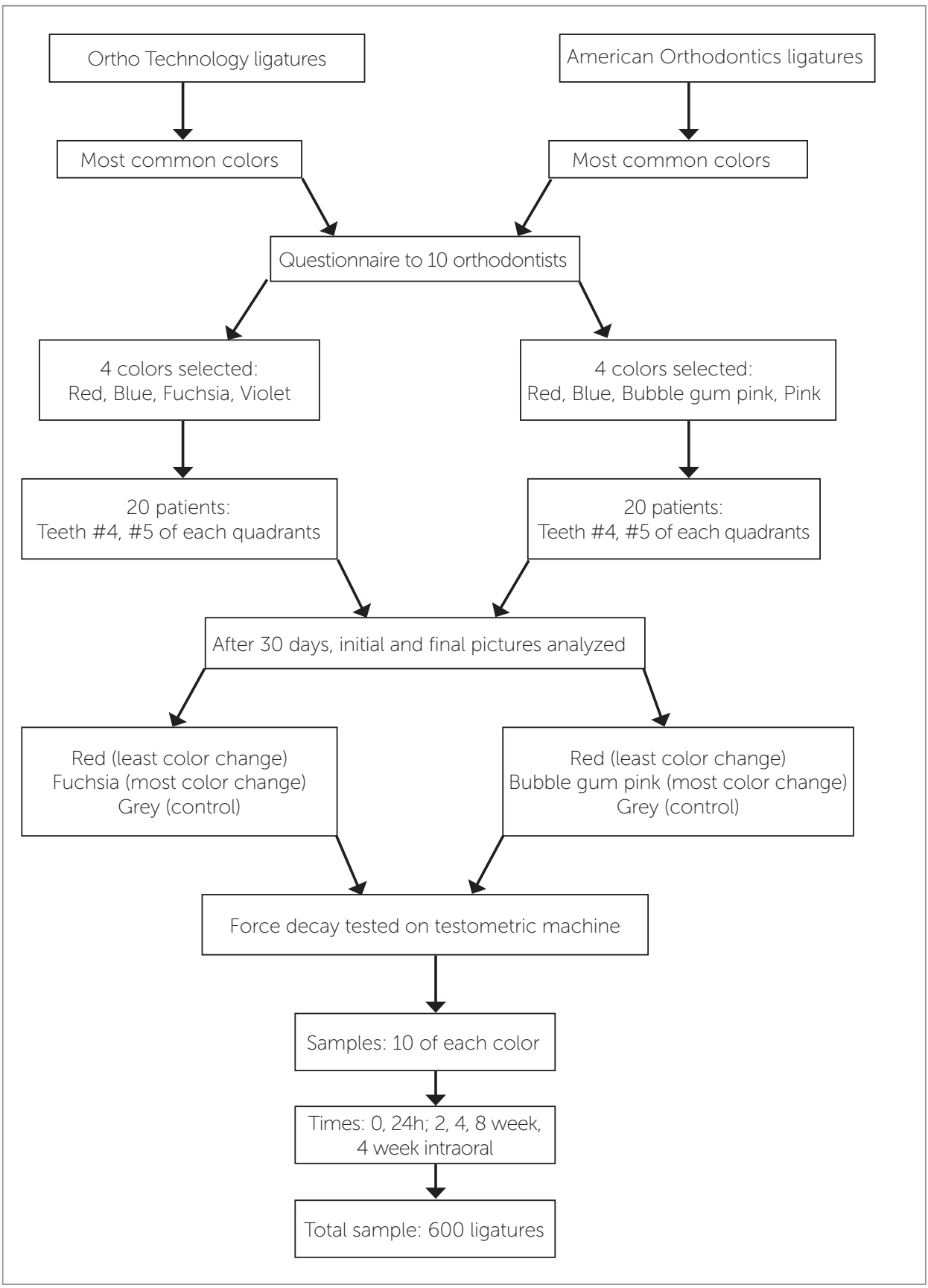

Figure 5 - Flow diagram of the study.

The results of four-way ANOVA showed that all four variables (commercial brand, color, time and stretching pattern) had significant effects on the force levels of the elastomers $(p<0.001)$ (Table 2).

The mean residual forces and mean percentages of force degradation for elastomeric ligatures of each brand are summarized in Table 3. Mean elastomers residual force in all experimental groups after 4 and 8 weeks were, respectively, in the following ranges: $1.07-2.28 \mathrm{~N}$ and $1.14-1.64 \mathrm{~N}$. After 8 weeks, the minimum residual forces were recorded for the AO bubble-gum pink elastomers $(1.29 \pm 0.56 \mathrm{~N})$ and OT fuchsia elastomers $(1.15 \pm 0.37 \mathrm{~N})$, with no significant differences. The maximum residual forces were also recorded for the gray elastomers of both companies (Table 3). 
Table 2 - Test of between-subjects effects using 4-way ANOVA statistical analysis.

\begin{tabular}{|c|c|c|c|c|c|}
\hline Subjects & $\begin{array}{c}\text { Type III Sum } \\
\text { of Square }\end{array}$ & fd & $\begin{array}{l}\text { Mean } \\
\text { Square }\end{array}$ & F-Value & P-Value \\
\hline Color & .989 & 65 & .494 & 7.215 & .001 \\
\hline Brand & 6.891 & 1 & 6.891 & 100.592 & .000 \\
\hline Time & 597.210 & 2 & 149.303 & 2,179 & .000 \\
\hline Storage & 4.275 & 1 & 2.137 & 31.199 & .000 \\
\hline Color*Brand & .466 & 4 & .233 & 3.404 & .034 \\
\hline Color*Time & 16.189 & 2 & 2.024 & 29.539 & .000 \\
\hline Color*Tensile & 1.658 & 2 & .414 & 6.050 & .000 \\
\hline Brand*Time & 9.833 & 8 & 2.458 & 35.882 & .000 \\
\hline Brand*Tensile & 6.687 & 4 & 3.343 & 48.803 & .000 \\
\hline Time*Tensile & 10.452 & 4 & 2.613 & 38.142 & .000 \\
\hline Color*Brand*Time & 3.228 & 2 & .403 & 5.890 & .000 \\
\hline Color*Brand*Tensile & 3.950 & 4 & .988 & 14.415 & .000 \\
\hline Color*Time*Tensile & 3.671 & 8 & .459 & 6.699 & .000 \\
\hline Brand*Time*Tensile & 2.298 & 4 & .574 & 8.386 & .000 \\
\hline Color*Brand*Time*Tensile & 2.675 & 8 & .334 & 4.880 & .000 \\
\hline Total & 3.919 .722 & 621 & & & \\
\hline
\end{tabular}

Table 3 - Mean residual force (N) and mean percentage of force decay for all test groups.

\begin{tabular}{|c|c|c|c|c|c|c|c|c|c|c|c|}
\hline & \multirow[b]{2}{*}{ Color } & \multirow{2}{*}{$\begin{array}{l}\text { Type of } \\
\text { traction }\end{array}$} & \multicolumn{5}{|c|}{ Residual force (mean $\pm S D$ ) } & \multicolumn{4}{|c|}{ Mean percentage of force decay (\%) } \\
\hline & & & 0 & $\begin{array}{c}24 \\
\text { hours }\end{array}$ & $\begin{array}{c}2 \\
\text { weeks }\end{array}$ & $\begin{array}{c}4 \\
\text { weeks }\end{array}$ & $\begin{array}{c}8 \\
\text { weeks }\end{array}$ & $\begin{array}{c}24 \\
\text { hours }\end{array}$ & $\begin{array}{c}4 \\
\text { weeks }\end{array}$ & $\begin{array}{c}8 \\
\text { weeks }\end{array}$ & $\begin{array}{l}4 \text { weeks } \\
\text { Intraoral }\end{array}$ \\
\hline \multirow{6}{*}{$\begin{array}{c}\text { Ortho } \\
\text { Technology }\end{array}$} & \multirow[t]{2}{*}{ Red } & Omm & $3.598 \pm .362$ & $2.522 \pm .362$ & $2.054 \pm .362$ & $1.469 \pm .128$ & $1.272 \pm .472$ & 30 & 59 & 65 & $1.252 \pm .125$ \\
\hline & & $1 \mathrm{~mm}$ & $4.176 \pm .338$ & $2.363 \pm .132$ & $1.618 \pm .135$ & $1.423 \pm .168$ & $1.616 \pm .175$ & 43.5 & 66 & 61.5 & $65.21 \%$ \\
\hline & \multirow{2}{*}{ Gray } & Omm & $3.162 \pm .391$ & $2.134 \pm .362$ & $1.658 \pm .202$ & $1.782 \pm .327$ & $1.089 \pm .107$ & 32.6 & 43.7 & 65.6 & $1.780 \pm .289$ \\
\hline & & $1 \mathrm{~mm}$ & $3.577 \pm .416$ & $1.958 \pm .180$ & $1.641 \pm .132$ & $1.480 \pm .154$ & $1.641 \pm .158$ & 45.3 & 58.7 & 54.2 & $43.71 \%$ \\
\hline & \multirow[t]{2}{*}{ Fuchsia } & $\mathrm{Omm}$ & $3.803 \pm .232$ & $2.127 \pm .358$ & $1.685 \pm .135$ & $1.702 \pm .100$ & $1.148 \pm .129$ & 44 & 55.3 & 69.9 & $1.055 \pm .783$ \\
\hline & & $1 \mathrm{~mm}$ & $4.247 \pm .240$ & $1.722 \pm .106$ & $1.608 \pm .152$ & $1.071 \pm .615$ & $1.150 \pm .375$ & 59.5 & 74.8 & 72.8 & $72.26 \%$ \\
\hline \multirow{6}{*}{$\begin{array}{c}\text { American } \\
\text { Orthodontics }\end{array}$} & \multirow{2}{*}{ Red } & $\mathrm{Omm}$ & $4.684 \pm .217$ & $2.385 \pm .230$ & $2.036 \pm .141$ & $1.545 \pm .247$ & $1.493 \pm .371$ & 49 & 67 & 68 & $1.348 \pm .115$ \\
\hline & & $1 \mathrm{~mm}$ & $5.269 \pm .228$ & $2.309 \pm .096$ & $2.224 \pm .147$ & $1.713 \pm .086$ & $1.598 \pm .278$ & 56 & 67.5 & 69.7 & $71.2 \%$ \\
\hline & \multirow{2}{*}{ Gray } & $\mathrm{Omm}$ & $3.883 \pm .469$ & $2.635 \pm .315$ & $2.080 \pm .170$ & $2.285 \pm .511$ & $1.613 \pm .126$ & 32.2 & 41.2 & 58.5 & $1.143 \pm .713$ \\
\hline & & $1 \mathrm{~mm}$ & $4.418 \pm .464$ & $2.315 \pm .133$ & $2.016 \pm .165$ & $1.952 \pm .212$ & $1.588 \pm .132$ & 47.7 & 55.9 & 64.1 & $63.15 \%$ \\
\hline & \multirow{2}{*}{$\begin{array}{l}\text { Bubble- } \\
\text { gum } \\
\text { pink }\end{array}$} & $\mathrm{Omm}$ & $4.541 \pm .513$ & $2.518 \pm .319$ & $1.812 \pm .075$ & $1.580 \pm .107$ & $1.295 \pm .567$ & 44.6 & 65.3 & 71.5 & $1.442 \pm .116$ \\
\hline & & $1 \mathrm{~mm}$ & $5.191 \pm .554$ & $2.530 \pm .133$ & $2.313 \pm .143$ & $1.701 \pm .133$ & $1.411 \pm .131$ & 51.3 & 67.3 & 72.82 & $68.25 \%$ \\
\hline
\end{tabular}


In all ligatures of both companies and two different stretch pattern groups, the greatest rate of force decay occurred during the first 24 hours. At 0-4-week interval, the percentages of force degradation in all the elastomers were higher in the '1-mm stretch' groups than the 'uniform stretch' groups. Comparison of the residual forces in the intraoral elastomers with those of the in vitro evaluation at 4 -week interval showed that the residual forces in the intraoral elastomers in all the groups were smaller than those studied in vitro; however, the differences were clinically significant only in the OT fuchsia elastomers $(0.7 \mathrm{~N})$ and $\mathrm{AO}$ gray elastomers $(1.14 \mathrm{~N})$.

\section{DISCUSSION}

The results of the present study confirmed that elastomeric ligatures with different color under different stretching patterns have different force decay rates.

$\mathrm{OT}$ fuchsia elastomers and $\mathrm{AO}$ red elastomers, which had the maximum initial forces, exhibited maximum force degradation during the first 24 hours followed by less force decay or relative force stability at subsequent intervals, compared to other elastomers, corroborating previous studies, which showed that elastomers producing higher initial forces displayed more force decay. ${ }^{9,11,12,13}$

The advantages of differentiating the elastomers with the minimum and the maximum color changes after exposure to oral environment not only provides results closer to the reality but also can help patient and clinician to choose the color and brand of elastomers that show greater esthetic stability during the period between two orthodontic follow-up appointments. In order to do so, in the process of selecting elastomers with maximum and minimum color changes - after a opinion poll with the clinicians that had used these products for a considerable time - , and for higher data accuracy, the elastomers were placed in the oral cavity and all the factors affecting color change process (through simple staining and chemical degradation, including foodstuffs, temperature changes and oral bacterial flora) were taken into account and the results were very close to real clinical situations. ${ }^{3}$

The aim of this study was to determine clinically noticeable discoloration of elastomers. Digital camera was used because it is a more cost-effective and simpler process than the use of traditional methods such as spectrophotometry. ${ }^{14,15}$ Also, there is a very high and statis- tically significant correlation between the traditional method and digital camera. ${ }^{16}$ Another reason to use digital photography to evaluate color change, compared with other complex procedures, is that it is a practical method, reproducible by professional in clinical conditions. For these reasons, digital photographs were used to compare discolorations of elastomeric ligatures before and after exposure to the oral environment.

Lam et $\mathrm{al}^{17}$ results were similar to the findings of the present study: they reported that addition of pigments to elastomers can change their mechanical properties. Since the fuchsia and bubble-gum pink elastomers exhibited maximum color changes in the oral cavity and also maximum force loss under the circumstances of the present study, it might be hypothesized that there is correlation between elastomer color changes and the amount of force loss, but this theory also needs to be evaluated in different brands of elastomers and different study condition.

The force degradation pattern of elastomers in the intra- and extraoral stages of the study was the same. However, the amount of intraoral residual forces in $\mathrm{AO}$ gray and OT fuchsia elastomers exhibited a significant decrease, compared to in vitro conditions. Eliades et a $1^{18}$ evaluated the tensile properties of elastomeric chains and showed no significant differences between the intraoral and laboratory conditions, consistent with the results of the present study. However, Ash et a ${ }^{19}$ showed significantly lower residual forces in the elastomeric chains placed in the oral cavity compared to samples placed under atmospheric conditions; although there were minor differences in forces in elastomers placed in water and in the oral cavity. Such differences might be attributed to the lack of similarity between the conditions of in vitro and in vivo studies.

The dimensional accuracy of the storage jigs, and also the use of artificial saliva and conserving the elastomers at $37^{\circ} \mathrm{C}$ resulted in the similarity of the results of intra- and extraoral stages of study. It should be pointed out that the elastomers were placed in the oral cavity on the premolar teeth in the finishing stage of treatment, during which the teeth exhibit sufficient leveling and alignment, which is similar to the in vitro conditions in the uniform stretch pattern. It was not possible to simulate the $1-\mathrm{mm}$ point stretch condition in the oral cavity due to differences in teeth positions in the early stages of treatment and it was not possible to match the tension and stress conditions in the elastomers. 
During the first stage of fixed orthodontic treatment, some stress concentration points are created in elastomers due to the misalignment of the dentition and differences in the buccolingual positions of adjacent teeth. In the present study, 1-mm point stretch storage jigs were designed and fabricated using a CAD-CAM technique, with the dimensional accuracy of up to $0.1 \mathrm{~mm}$, to simulate the first stage of treatment.

Another advantage of the present study in comparison to some previous studies ${ }^{13,18,20}$ was selection of the $0-8$-week interval. Sims et $\mathrm{al}^{21}$ stated that a single elastic module produces a ligation force of 50-150 g. Therefore, the results of the present study showed that the residual forces in all the tested groups after 8 weeks $(142 \pm 23 \mathrm{~g}$ and $149 \pm 11 \mathrm{~g}$ in OT and AO elastomers, respectively) were adequate to hold the wire within the bracket slot and make it possible to arrange inter-appointment intervals longer than four weeks during the early stages of orthodontic treatment (in cases where there is no concern regarding plaque accumulation), which makes the treatment process more cost-effective for both the patient and the clinician. Peterson et $\mathrm{al}^{22}$ reported that if ligation or normal forces decrease, there will be a corresponding decrease in frictional resistance, so in other words higher forces in elastomers result in higher frictional forces in the system, decreasing tooth movement rate in early stage of treatment. ${ }^{23}$ Contrarily, this high amount of force decays after 8 weeks. The elastomeric modules are not good candidates for remaining in oral cavity more than 4 weeks in the final stages of fixed orthodontic treatment, in which the wire should be completely and actively seated in the bracket slot.
Under the terms of our study on two brands of elastomers, it seems that incorporation of different pigments into elastomers affects force degradation rates by affecting the amount of the initial forces. Therefore, further studies on other brands of elastomers are required to evaluate the correlation between the characteristics of elastomers, which can be observed in the clinic and the mechanical properties of these elastic materials. It is possible to match the results of in vitro and in vivo studies by exact simulation of in vitro conditions of studies. However, to determine the amount of ligation force produced by elastomers and force decay rate and their correlation with elastomer size, elastomer brand, color, time, stage of treatment, etc, further intraoral studies are required.

\section{CONCLUSION}

1. All the ligatures showed an unwanted color changes after exposure to intraoral environment, although American Orthodontics ( $\mathrm{AO}$ ) red and blue elastomers and Ortho Technology (OT) cobalt blue and red elastomers showed minimum color changes.

2. The results of the present study showed a significant relationship between the stretching pattern and the amount of residual force of elastomeric ligatures.

3. Elastomers with higher initial forces exhibited higher percentages of force decay after 8 weeks.

4. In the elastomers evaluated in this study, the maximum force decay occurred during the first 24 hours continuing at lower rates during the 8 weeks period. 


\section{REFERENCES}

1. Carneiro GKM, Roque JA, Garcez Segundo AS, Suzuki H. Evaluation of stiffness and plastic deformation of active ceramic self-ligating bracket clips after repetitive opening and closure movements. Dental Press J Orthod. 2015 July-Aug:20(4):45-5.

2. Walton DK, Fields HW, Johnston WM, Rosenstiel SF, Firestone AR, Christensen JC. Orthodontic appliance preferences of children and adolescents. Am J Orthod Dentofacial Orthop. 2010 Dec;138(6):698.e1-12; discussion 698-9

3. Buchmann N. Senn C, Ball J, Brauchli L. Influence of initial strain on the force decay of currently available elastic chains over time. Angle Orthod. 2012 May; 82(3):529-35

4. Eliades T, Bourauel C. Intraoral aging of orthodontic materials: the picture we miss and its clinical relevance. Am J Orthod Dentofacial Orthop. 2005 Apr:127(4):403-12.

5. Ardeshna AP, Vaidyanathan TK. Colour changes of orthodontic elastomeric module materials exposed to in vitro dietary media. J Orthod. 2009 Sept:36(3):177-85.

6. Oliveira AS, Kaizer MR, Salgado VE, Soldati DC, Silva RC, Moraes RR. Influence of whitening and regular dentifrices on orthodontic clear ligature color stability. J Esthet Restor Dent. 2015 Mar-Apr;27 Suppl 1:S58-64

7. Kim SH, Lee YK. Measurement of discolouration of orthodontic elastomeric modules with a digital camera. Eur J Orthod. 2009 Oct;31(5):556-62.

8. Silva DL, Mattos CT, Araújo MV, Ruellas ACO. Color stability and fluorescence of different orthodontic esthetic archwires. Angle Orthod. 2013 Jan; 83(1):127-32

9. Masoud Al, Bulic M, Viana G, Bedran-Russo AK. Force decay and dimensional changes of thermoplastic and novel thermoset elastomeric ligatures. Angle Orthod. 2016 Sept;86(5):818-25.

10. Kovatch JS, Lautenschlager EP, Apfel DA, Keller JC. Load-extension-time behavior of orthodontic alastiks. J Dent Res. 1976 Sept-Oct;55(5):783-6.

11. Stevenson JS, Kusy RP. Force application and decay characteristics of untreated and treated polyurethane elastomeric chains. Angle Orthod 1994;64(6):455-64; discussion 465-7.

12. Tonks M, Millett $P$, Cai $W$, Wolf $D$. Analysis of the elastic strain energy driving force for grain boundary migration using phase field simulation. Scr Mater. 2010:63(11):1049-52
13. Dowling PA, Jones WB, Lagerstrom L, Sandham JA. An investigation into the behavioural characteristics of orthodontic elastomeric modules. $\mathrm{Br} \mathrm{J}$ Orthod. 1998 Aug:25(3):197-202

14. Cal E, Sonugelen M, Guneri P, Kesercioglu A, Kose T. Application of a digital technique in evaluating the reliability of shade guides. J Oral Rehabil. 2004 May:31(5):483-91

15. Dozić A, Kleverlaan CJ, El-Zohairy A, Feilzer AJ, Khashayar G. Performance of five commercially available tooth color-measuring devices. J Prosthodont. 2007 Mar-Apr;16(2):93-100.

16. Jarad FD, Russell MD, Moss BW. The use of digital imaging for colour matching and communication in restorative dentistry. Br Dent J. 2005 July 9:199(1):43-9; discussion 33

17. Lam TV, Freer TJ, Brockhurst PJ, Podlich HM. Strength decay of orthodontic elastomeric ligatures. J Orthod. 2002 Mar:29(1):37-43.

18. Eliades T, Eliades G, Silikas N, Watts DC. Tensile properties of orthodontic elastomeric chains. Eur J Orthod. 2004 Apr:26(2):157-62.

19. Ash JL, Nikolai RJ. Relaxation of orthodontic elastomeric chains and modules in vitro and in vivo. J Dent Res. 1978 May-June;57(5-6):685-90

20. Dechkunakorn S, Viriyakosol N, Anuwongnukroh N, Suddhasthira T, Laokijcharoen P. Churnjitapirom P, et al. Residual force of orthodontic elastomeric ligature. Adv Mat Res. 2011;378-379:674-680.

21. Sims AP, Waters NE, Birnie DJ, Pethybridge RJ. A comparison of the forces required to produce tooth movement in vitro using two self-ligating brackets and a pre-adjusted bracket employing two types of ligation. Eur J Orthod. 1993 Oct:15(5):377-85

22. Petersen A, Rosenstein S, Kim KB, Israel H. Force decay of elastomeric ligatures: influence on unloading force compared to self-ligation. Angle Orthod. 2009 Sept:79(5):934-8

23. Bortoly TG, Guerrero AP, Rached RN, Tanaka O, Guariza-Filho O, Rosa EA Sliding resistance with esthetic ligatures: an in-vitro study. Am J Orthod Dentofacial Orthop. 2008 Mar:133(3):340.e1-7. 